\begin{tabular}{|c|c|c|c|}
\hline \multirow{2}{*}{$\begin{array}{r}\text { Case Reports in } \\
\text { Gastroenterology }\end{array}$} & \multicolumn{2}{|c|}{ Case Rep Gastroenterol 2015;9:200-205 } & \multirow[b]{2}{*}{$\begin{array}{l}\text { Karger } \\
\text { Open access }\end{array}$} \\
\hline & $\begin{array}{l}\text { DOI: } 10.1159 / 000431170 \\
\text { Published onine: June } 9,2015\end{array}$ & $\begin{array}{l}\text { (C) } 2015 \text { S. Karger AG, Basel } \\
1662-0631 / 15 / 0092-0200 \$ 39.50 / 0 \\
\text { www.karger.com/crg }\end{array}$ & \\
\hline & \multicolumn{2}{|c|}{$\begin{array}{l}\text { This is an Open Access article licensed under the terms of the Creative Commons } \\
\text { Attribution-NonCommercial } 3.0 \text { Unported license (CC BY-NC) (www.karger.com/OA } \\
\text { license), applicable to the online version of the article only. Distribution permitted for non } \\
\text { commercial purposes only. }\end{array}$} & \\
\hline
\end{tabular}

\title{
Rare Neurological Manifestation of Celiac Disease
}

\author{
Uzma Rani Aamer Imdad Mirza Beg \\ State University of New York Upstate Medical University, Syracuse, N.Y., USA
}

\section{Key Words}

Pseudotumor cerebri · Celiac disease · Transglutaminase IgA · Antiendomysial IgA

\begin{abstract}
Celiac disease (CD) is an immune-mediated disease characterized by permanent gastrointestinal tract sensitivity to gluten in genetically predisposed individuals. It has varied clinical manifestations, ranging from gastrointestinal to extraintestinal, including neurological, skin, reproductive and psychiatric symptoms, which makes its diagnosis difficult and challenging. Known neurological manifestations of CD include epilepsy with or without occipital calcification, attention deficit hyperactivity disorder and ataxia, headache, neuropathies and behavior disorders. We present the case of a 14-year-old female with headaches and blurred vision for 1 year; she was noted to have papilledema on ophthalmic examination with increased cerebrospinal fluid opening pressure on lumber puncture and was diagnosed as a case of pseudotumor cerebri (PTC). Meanwhile her workup for chronic constipation revealed elevated tissue transglutaminase IgA and antiendomysial IgA antibodies. Upper gastrointestinal endoscopy with duodenal biopsy confirmed the diagnosis of $C D$. The patient was started on a gluten-free diet, leading to resolution of not only gastrointestinal symptoms but also to almost complete resolution of symptoms of PTC. This report describes the correlation of CD and PTC as its neurological manifestation.

(c) 2015 S. Karger AG, Basel
\end{abstract}

\section{Introduction}

Celiac disease (CD) is an immune-mediated disease first described by a Greek physician who used the term abdominal diathesis as its clinical manifestation in $100 \mathrm{AD}$ [1]. However, the etiology of this disease remained unknown until 1953, when Dicke et al. [2] noticed that some factor in wheat had a deleterious effect in patients with CD. CD is the most common 
Rani et al.: Rare Neurological Manifestation of Celiac Disease

genetic food intolerance in the world, affecting $1 \%$ of the world population, with a predilection towards females [3]. Common gastrointestinal signs and symptoms include chronic diarrhea, chronic constipation, nausea, vomiting, abdominal pain and distention and weight loss [4]. Extraintestinal manifestations might include failure to thrive, stunted growth, delayed puberty, iron deficiency anemia, arthritis, arthralgia, dental enamel defects, elevated liver enzymes, decreased bone mineralization, recurrent mouth ulcers, amenorrhea, dermatitis herpetiformis, irritability, chronic fatigue, depression and anxiety [4]. CD has been linked to a variety of neurological conditions including epilepsy, cerebellar ataxia, chronic neuropathies, myoclonic ataxia, progressive leukoencephalopathy and dementia [5].

Pseudotumor cerebri (PTC) is a disorder characterized by signs and symptoms of increased intracranial pressure such as headache and papilledema, with lack of a structural defect such as an intracranial mass, injury or ventricular dilatation. Neurological examination is usually normal except for papilledema and rarely abducens nerve palsy. We present a case of CD that initially presented as PTC.

\section{Case Report}

A 14-year-old Caucasian female came to the emergency room with complaints of headache and blurred vision for 1 year that had recently worsened. Headache was in the occipital and frontal region, continuous, pressure-like, non-radiating and not associated with nausea or vomiting. There were no aggravating or relieving factors. She also had blurring of vision in both eyes, but more on the left side, along with pain and redness of the left eye. On review of systems she has no complaint of weakness, numbness, shortness of breath or palpitation. There was no history of trauma. Her past medical history revealed intermittent complaint of constipation for which she was taking a high-fiber diet and laxatives. Her family history showed glaucoma in her paternal grandfather. Her menarche was at the age of 9 years. Physical examination showed blood pressure $120 / 80 \mathrm{~mm} \mathrm{Hg}$, pulse $78 / \mathrm{min}$, temperature $37^{\circ} \mathrm{C}$ and respiratory rate 18/min. Her head circumference was $57 \mathrm{~cm}$, she was awake and alert, oriented to time place and person. Her weight was 159 pounds $(72 \mathrm{~kg})$, her height 5 feet 1 inch and her body mass index $30 \mathrm{~kg} / \mathrm{m}^{2}$. Respiratory, abdominal, cardiovascular and neurological examinations were normal. Ophthalmological examination showed decreased visual acuity (20/200 on the left side and 20/40 on the right side). Significant bilateral papilledema was found on fundoscopic examination of the eyes, with vessel obscuration and tortuosity of vessels. Magnetic resonance imaging (fig. 1) and magnetic resonance venography of the brain showed normal results. Lumber puncture was performed and showed a cerebrospinal fluid opening pressure of $29 \mathrm{~cm} \mathrm{H}_{2} \mathrm{O}$ (normal $<20 \mathrm{~cm} \mathrm{H}_{2} \mathrm{O}$ ); however protein, glucose and cell count of cerebrospinal fluid were within normal limits.

Based on these investigations a diagnosis of PTC was made and the patient was started on a diuretic (acetazolamide $750 \mathrm{mg}$ p.o. twice a day) and advised to lose weight. One month after this visit, the patient was referred to the pediatric gastroenterology clinic for evaluation of abdominal pain due to severe constipation with no bowel movement for 3 days. Pain was described as diffuse, dull and non-radiating, with no aggravating or relieving factors. Physical examination of her abdomen revealed that it was soft and non-tender without visceromegaly. As she had a long history of intermittent constipation with no response to treatment, further workup was performed. This included complete blood counts, erythrocyte sedimentation rate, serum iron, vitamin D levels, urinalysis, serum electrolytes and thyroid studies, and these were reported to be within normal range. Serology for CD showed elevated levels of antiendomysial and tissue transglutaminase IgA antibodies and normal IgA levels. Upper 
Rani et al.: Rare Neurological Manifestation of Celiac Disease

gastrointestinal endoscopy with biopsy was performed. Histopathological examination of the duodenal mucosa showed mild villous blunting and crypt hyperplasia with distended lamina propria and increased plasma cells and increased intraepithelial lymphocytes, confirming the diagnosis of CD (fig. 2, fig. 3).

The patient was started on a gluten-free diet. On follow-up after 2 months she had complete resolution of constipation. She also reported that she had discontinued acetazolamide due to a remarkable decrease in frequency and severity of headache and blurred vision. Her ophthalmological examination showed visual acuity of 20/20 in both eyes and significantly decreased swelling of the optic disc compared to the previous fundoscopic examination described above, with no vessel obscuration despite the fact that her body mass index was unchanged $\left(30 \mathrm{~kg} / \mathrm{m}^{2}\right)$. She was continued on a gluten-free diet, and acetazolamide at a decreased dose of $250 \mathrm{mg}$ twice a day (compared to $750 \mathrm{mg}$ b.i.d. at the time of presentation) was re-started by the neuro-ophthalmologist. Her recent follow-up showed complete resolution of headache and blurred vision with no optic disc swelling.

\section{Discussion}

$\mathrm{CD}$, also known as gluten enteropathy, is an inflammatory autoimmune disease of the small bowel characterized by sensitivity to gluten, a storage protein in wheat, barley and rye. Its etiology is considered to be multifactorial, comprising genetic, immunological and environmental factors. Major histocompatibility complex alleles expressing HLADQ2 and HLADQ8 are present in more than $90-95 \%$ of diagnosed CD patients [6]. The disease prevalence is $8-12 \%$ in first-degree relatives of affected individuals [6]. Environmental factors include gluten ingestion. Viral infection, pregnancy, high-dose gluten challenge and gastrointestinal surgery may increase the immunological response and can lead to precipitation of CD symptoms [7].

Silent CD is defined as presence of CD-specific antibodies, HLA genotype and small bowel biopsy findings consisting with $\mathrm{CD}$, but absence of gastrointestinal clinical features sufficient for suspicion of CD [8]. Latent CD is defined as presence of associated HLA complex in the absence of enteropathy in patients who have had gluten-dependent enteropathy at some point in their lives [8]. These patients may or may not have CD-specific antibodies or clinical features of CD. Potential CD is defined as presence of associated HLA complexes and antibodies, but no histological features of CD on small intestine biopsy. These patients may or may not have clinical features or gluten-dependent enteropathy later in their lives. Atypical CD presents with the extraintestinal manifestations of CD dominating over the classic symptoms [8].

Neurological manifestation of CD were first described by Cooke and Smith in 16 patients in 1966 [9]. Since then several conditions have been reported in association with CD, such as epilepsy, ataxia, cerebellar ataxia, anxiety, depression, encephalitis, occipital calcification, peripheral neuropathy, neuromuscular disorders, dementia, learning disorders such as attention deficit hyperactivity disorder, developmental delay and migraine [9]. PTC has rarely been described in association with CD. PTC syndrome, also known as idiopathic intracranial hypertension, is characterized by headache, papilledema and normal neurological examination except for cranial nerve palsies and increased intracranial pressure, in the absence of any structural abnormality of the central nervous system. In adults the upper limit of opening increased intracranial pressure is $25 \mathrm{~cm} \mathrm{H}_{2} \mathrm{O}$, while in obese and sedated children this limit is $28 \mathrm{~cm} \mathrm{H}_{2} \mathrm{O}$ [10]. The disease has a preponderance towards females with male:female ratio of 1:3 in adults and adolescent, but there is no predilection before puberty. PTC is asso- 
Rani et al.: Rare Neurological Manifestation of Celiac Disease

ciated with recent weight gain that is usually acquired 12 months prior to diagnosis. The annual incidence of PTC in the general population is $0.5-1 / 100,000$ [11]. Fewer epidemiological data are available for pediatric PTC, however a German study has shown an incidence of $0.5 / 100,000[11,12]$.

Dotan et al. [13] reported 6 cases of pediatric PTC and described their possible association with nutritional/gastrointestinal factors. All of these 6 cases were found to have low serum vitamin A levels in contrast to the previous hypothesis of hypervitaminosis A causing PTC. Further investigations were done to know the cause of low vitamin A levels, showing self-restriction of diet in 2 patients with autism, malabsorption secondary to CD in 2 patients and unknown etiology in the remaining patients.

In our case, the patient had an initial presentation with classic symptoms of PTC, but later presented to the pediatric gastroenterology clinic for evaluation of constipation and was found to have $\mathrm{CD}$. When she was started on a gluten-free diet, it not only improved gastrointestinal but also neurological symptoms. We thought that her neurological symptoms might have been related to her CD. Even though she was prescribed acetazolamide for PTC and was not compliant with medication, her signs and symptoms improved with introduction of a gluten-free diet. As described previously by Dotan et al. [13], her neurological symptoms could have been caused by malabsorption of a vitamin, such as vitamin A. As her CD improved, her micronutrient deficiency might have been corrected, improving her neurological symptoms. This is contrast to observations made by Ghazal et al. [14], where the patient presented with neurological symptoms and did not have active enteropathy but had potential CD. Authors described a possible immunological cause of neurological symptoms in CD. In any case, the exact mechanism of the relationship between $\mathrm{CD}$ and neurological symptoms is not well established at this time and requires further research work.

We present this case to emphasize that $\mathrm{CD}$ should be considered in the differential diagnosis of the etiology of PTC. This can lead to early diagnosis and possible treatment of both conditions and prevention of complications of CD and PTC.

\section{References}

1 Aretaeus. Liber IV. Celiac diathesis, in Corpus Medicorum Graecorum, Berlin; Akademie-Verlag GmbH, 1956; 74.

-2 Dicke WK, Weijers HA, van de Kamer JH: Coeliac disease. II. The presence in wheat of a factor having a deleterious effect in cases of coeliac disease. Acta Paediatr 1953;42:34-42.

-3 Guandalini S, Assiri A: Celiac disease: a review. JAMA Pediatr 2014;168:272-278.

4 National Institute for Health and Clinical Excellence: Coeliac disease: recognition and assessment of coeliac disease. London, National Institute for Health and Clinical Excellence, 2009.

-5 Zelnik N, Pacht A, Obeid R, Lerner A: Range of neurologic disorders in patients with celiac disease. Pediatrics 2004;113:1672-1676.

6 Trier JS: Chapter 20: Intestinal malabsorption; in Greenberger NJ, Blumberg RS, Burakoff R (eds): CURRENT Diagnosis and Treatment: Gastroenterology, Hepatology, \& Endoscopy. New York, McGraw-Hill, 2012.

7 Murray JA: The widening spectrum of celiac disease. Am J Clin Nutr 1999;69:354-365.

-8 Husby S, Koletzko S, Korponay-Szabó IR, Mearin ML, Phillips A, Shamir R, Troncone R, Giersiepen K, Branski D, Catassi C, Lelgeman M, Mäki M, Ribes-Koninckx C, Ventura A, Zimmer KP; ESPGHAN Working Group on Coeliac Disease Diagnosis; ESPGHAN Gastroenterology Committee; European Society for Pediatric Gastroenterology, Hepatology, and Nutrition: European Society for Pediatric Gastroenterology, Hepatology, and Nutrition guidelines for the diagnosis of coeliac disease. J Pediatr Gastroenterol Nutr 2012;54:136-160.

-9 Cooke WT, Smith WT: Neurological disorders associated with adult coeliac disease. Brain 1966;89:683-722.

10 Avery RA, Shah SS, Licht DJ, Seiden JA, Huh JW, Boswinkel J, Ruppe MD, Chew A, Mistry RD, Liu GT: Reference range for cerebrospinal fluid opening pressure in children. N Engl J Med 2010;363:891-893.

11 Durcan FJ, Corbett JJ, Wall M: The incidence of pseudotumor cerebri. Population studies in Iowa and Louisiana. Arch Neurol 1988;45:875-877.

12 Tibussek D, Distelmaier F, von Kries R, Mayatepek E: Pseudotumor cerebri in childhood and adolescence results of a Germany-wide ESPED-survey. Klin Padiatr 2013;225:81-85. 
Rani et al.: Rare Neurological Manifestation of Celiac Disease

13 Dotan G, Goldstein M, Stolovitch C, Kesler A: Pediatric pseudotumor cerebri associated with low serum levels of vitamin A. J Child Neurol 2013;28:1370-1377.

14 Ghazal FA, Singh S, Yaghi S, Keyrouz SG: Gluten ataxia: an important treatable etiology of sporadic ataxia. Int J Neurosci 2012;122:545-546.

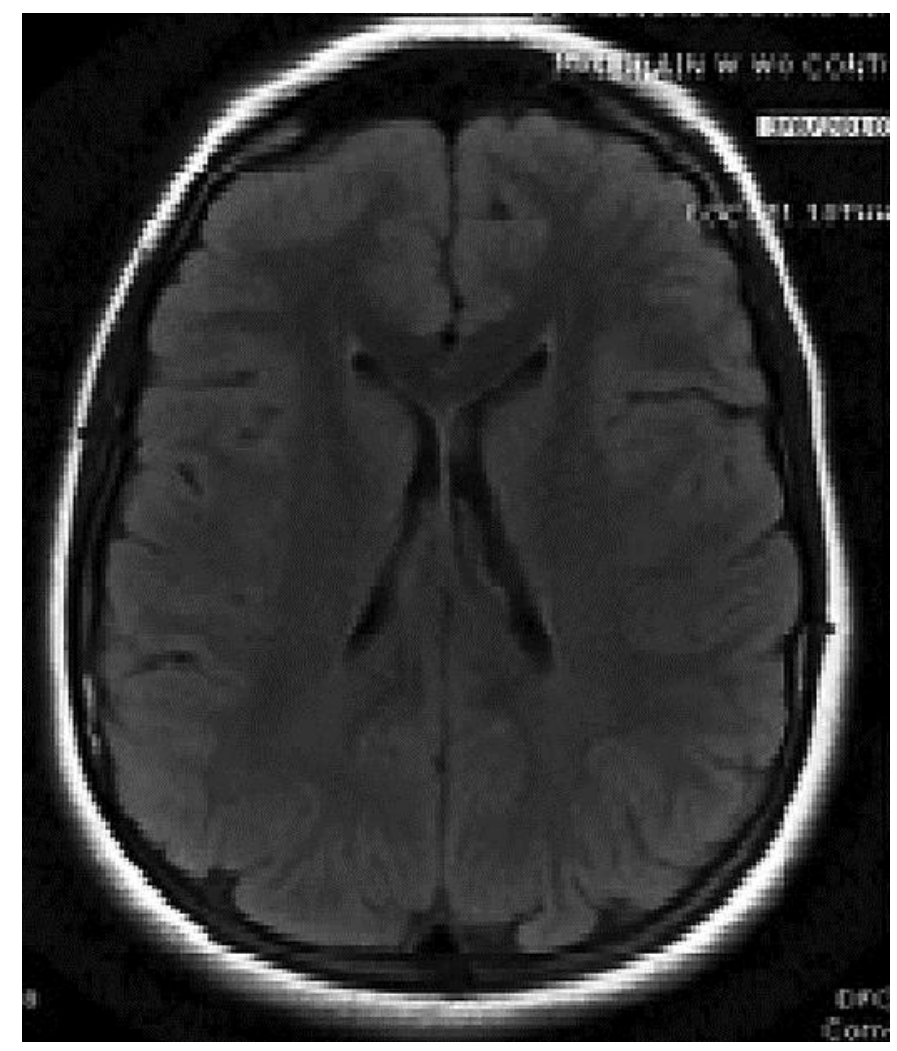

Fig. 1. Magnetic resonance imaging of the brain showing intact brain structures with no signs of obstructive hydrocephalus. 
Rani et al.: Rare Neurological Manifestation of Celiac Disease

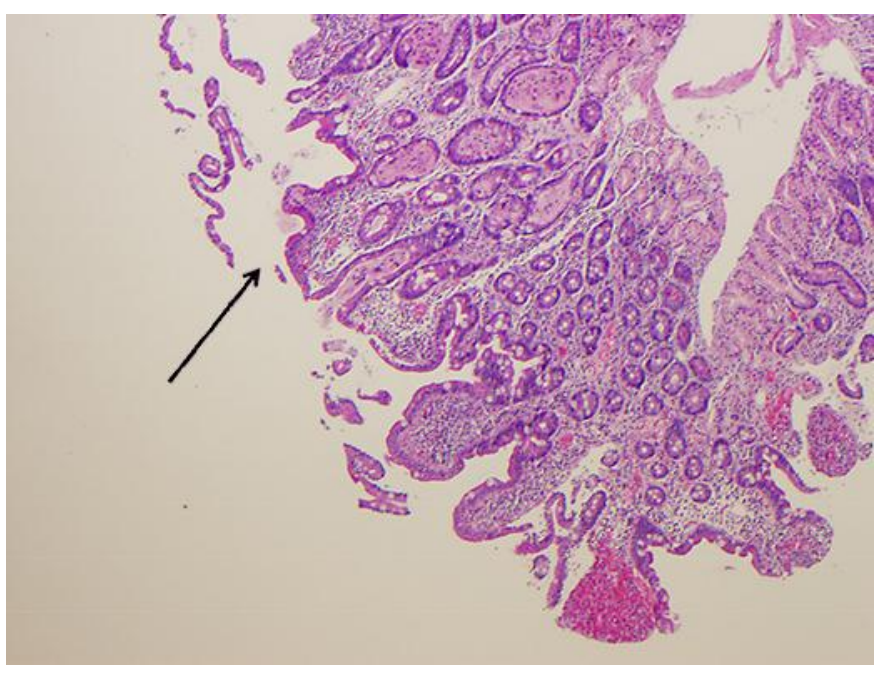

Fig. 2. Low power $(\mathrm{H} \& \mathrm{E}, \times 4)$ showing blunting of the villi (arrow) and increased inflammatory cells in the lamina propria and epithelium.

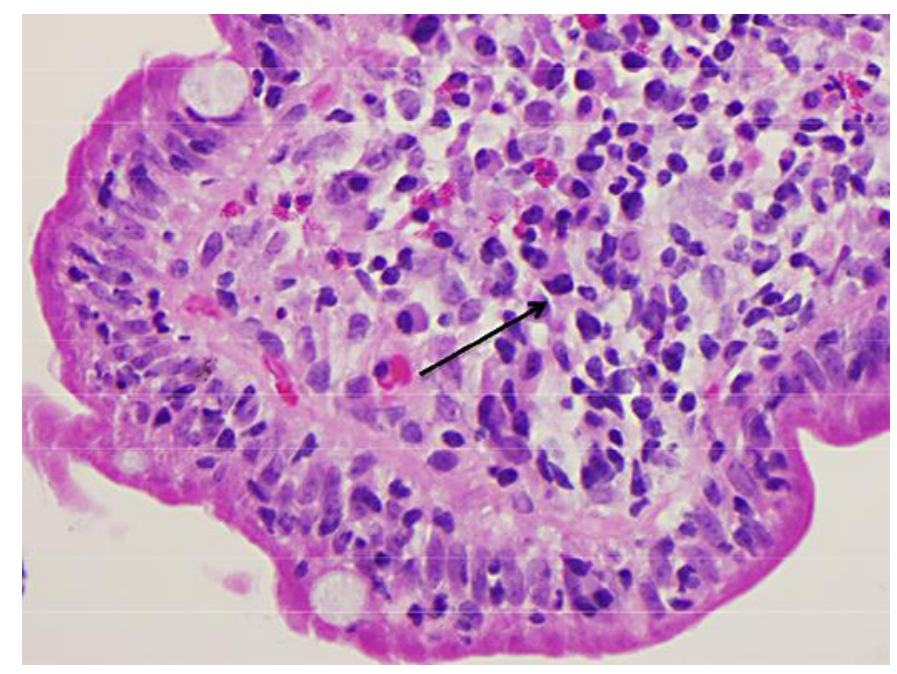

Fig. 3. Higher power $(H \& E, \times 40)$ showing increased intraepithelial lymphocytes (arrow) most pronounced at the tips of the villi. 